\title{
Bactérias promotoras de crescimento em plantas aliada a adubação nitrogenada na produção de milho doce ${ }^{1}$
}

\author{
Jamille de Lima Rodrigues ${ }^{2}$, Ewerton Cavalcante Massena ${ }^{2}$, Antônio Lucrécio dos Santos Neto ${ }^{3}$, \\ Ademária Aparecida de Souza ${ }^{3}$, Ricardo Barros Silva ${ }^{3}$, Gleica Maria Correia Martins ${ }^{4}$
}

\begin{abstract}
Resumo: O cultivo do milho doce apresenta alta demanda de nitrogênio, e por ser uma cultura com grande potencial de expansão, são necessários estudos que demonstrem manejos eficientes da adubação nitrogenada para aumento de produtividade, como o uso de bactérias promotoras de crescimento de plantas capazes fixar nitrogênio atmosférico, desonerando o processo produtivo. Nesse trabalho objetivou-se avaliar a influência da bactérias promotoras de crescimento em plantas (BPCP) nativas do Sertão de Alagoas aliadas a adubação nitrogenada sob componentes de produção do milho doce. O delineamento estatístico utilizado foi em blocos casualizados, e os tratamentos foram BPCP e combinado com nitrogênio (N). A solução para inoculação foi constituída por bactérias pertencentes aos gêneros Pseudomonas $\left(\mathrm{SHS}_{2}, \mathrm{SHS}_{3}, \mathrm{SHS}_{9}\right)$, Bacillus $\left(\mathrm{AD}_{47}\right)$ e Enterobacter $\left(\mathrm{AD}_{3}\right)$. Assim, obteve-se os tratamentos: $\mathrm{T}_{1}=50 \%$ de N $+\mathrm{SHS}_{2}, \mathrm{~T}_{2}=50 \%$ de N $+\mathrm{SHS}_{3}, \mathrm{~T}_{3}=50 \%$ de N $+\mathrm{SHS}_{9}, \mathrm{~T}_{4}=50 \%$ de N $+\mathrm{AD}_{47}, \mathrm{~T}_{5}=50 \%$ de $\mathrm{N}+\mathrm{AD}_{3}, \mathrm{~T}_{6}=$ testemunha, $\mathrm{T}_{7}=100 \%$ de $\mathrm{N}, \mathrm{T}_{8}=50 \%$ de $\mathrm{N}$. A fonte de $\mathrm{N}$ utilizada foi ureia. Os componentes de produção avaliados foram: altura de planta, diâmetro do colmo, altura da inserção da espiga, índice de luminosidade, peso, diâmetro, comprimento com e sem palha, degrana da espiga, número de fileira de grãos na espiga, número de grãos por fileira, produtividade com palha, peso de palha, perda por degrana, peso de grãos por espiga e produtividade de grãos. De maneira geral, a adubação nitrogenada com $50 \%$ da dose recomendada em associação com BPCP mostrou-se viável, proporcionando produtividade igual estatisticamente a dose com $100 \%$ de $\mathrm{N}$ mineral ureia. Todos os tratamentos com nitrogênio em cobertura superaram a testemunha.
\end{abstract}

Palavras-chave: Zea mays cv. saccharata; Inoculantes; Nitrogênio; Produtividade de grãos.

\section{Plant growth-promoting bacteria associated with nitrogen fertilization in sweet corn production}

\begin{abstract}
The cultivation of sweet corn has a high demand for nitrogen, and because it is a crop with great expansion potential, studies are needed that demonstrate efficient management of nitrogen fertilization to increase productivity, such as the use of plant growth-promoting bacteria capable of fixing nitrogen atmospheric, exonerating the production process. This work aimed to evaluate the influence of growth promoting bacteria on plants (BPCP) native to the Sertão of Alagoas combined with nitrogen fertilization under components of sweet corn production. The statistical design used was in randomized blocks, and the treatments were BPCP and combined with nitrogen $(\mathrm{N})$. The inoculation solution consisted of bacteria belonging to the genera Pseudomonas $\left(\mathrm{SHS}_{2}, \mathrm{SHS}_{3}, \mathrm{SHS}_{9}\right)$, Bacillus $\left(\mathrm{AD}_{47}\right)$ and Enterobacter $\left(\mathrm{AD}_{3}\right)$. Thus, the treatments were obtained: $\mathrm{T}_{1}=50 \% \mathrm{~N}+$ $\mathrm{SHS}_{2}, \mathrm{~T}_{2}=50 \% \mathrm{~N}+\mathrm{SHS}_{3}, \mathrm{~T}_{3}=50 \% \mathrm{~N}+\mathrm{SHS}_{9}, \mathrm{~T}_{4}=50 \% \mathrm{~N}+\mathrm{AD}_{47}, \mathrm{~T}_{5}=50 \% \mathrm{~N}+\mathrm{AD}_{3}, \mathrm{~T}_{6}=$ control, $\mathrm{T}_{7}=100 \%$ $\mathrm{N}, \mathrm{T}_{8}=50 \% \mathrm{~N}$. The source of $\mathrm{N}$ used was urea. The production components evaluated were: plant height, stem diameter, ear insertion height, luminosity index, weight, diameter, length with and without straw, ear stalk, number of grains in the ear, number of grains per row, straw yield, straw weight, loss per crop, grain weight per ear and grain yield. In general, nitrogen fertilization with $50 \%$ of the recommended dose in association with BPCP proved to be viable, mineral urea. All treatments with nitrogen in coverage exceeded the control.
\end{abstract}

Keywords: Zea mays cv. saccharata; Inoculants; Nitrogen; Grain productivity.

\footnotetext{
${ }^{1}$ Submetido em 27/08/2020 e aprovado em 04/12/2020;

2Universidade Federal de Alagoas, Arapiraca, Alagoas, Brasil; E-mail: 9mlima@gmail.com; ewertonc46@gmail.com;

${ }^{3}$ Universidade Federal de Alagoas, Programa de Pós-Graduação em Agricultura e Ambiente, Arapiraca, Alagoas, Brasil; E-mail: santosneto@gmail.com - ORCID: https://orcid.org/0000-0003-1540-0202; ademariasouza@yahoo.com.br - ORCID: https://orcid.org/00000003-1540-0202; ricardoufal2010@gmail.com (Autor correspondente) - ORCID: https://orcid.org/0000-0002-0127-8325;
}

${ }^{4}$ Instituto Federal de Alagoas, Penedo, Alagoas, Brasil; E-mail: gleicamaria@ hotmail.com - ORCID: https://orcid.org/0000-0002-8696-9220 


\section{Introdução}

O milho doce (Zea mays subsp. saccharata) é uma olerícola de alto valor agregado, é destinado, principalmente, ao consumo humano devido ao sabor dos grãos (Luz et al., 2014) e a alta perecibilidade pós-colheita (Gondim et al., 2020). Comumente produzido nos Estados Unidos, Canadá e China, sua utilização está em contínuo crescimento por sua boa palatabilidade (Camilo et al., 2015). Essa olerícola se diferencia do milho comum pelo alto teor de açúcares presentes no endosperma (Aragão, 2002), característica essa resultante da ação de genes recessivos que bloqueiam a conversão de açúcares em amido (Ferreira et al., 2009).

No Brasil a produção do milho doce vem ganhando destaque, sendo consumido, principalmente, como milho verde, tanto na forma "in natura" como processado industrialmente para conservas alimentícias (Ferreira et al., 2011; Gondim et al., 2020). Cerca de $90 \%$ da área cultivada no país está concentrada no estado de Goiás, onde há condições edafoclimáticas favoráveis de cultivo durante todo o ano (Luz et al., 2014). No Brasil cerca de 36 mil hectares são destinados ao cultivo do milho doce, o que representa apenas $14,4 \%$ da área ocupada pelo milho doce dos Estados Unidos (Camilo et al., 2015). Essa pequena área destinada ao cultivo do milho doce no Brasil ocorre devido à alta exigência da cultura em manejo intensivo e insumos (fertilizantes, defensivos e sementes), o que onera o processo produtivo e reduz a capacidade de olericultores em produzi-la. Logo, estudos que objetivem substituir insumos que geram custos elevados de produção, como fertilizantes nitrogenados, são necessários, possibilitando o cultivo por pequenos e médios produtores, principais classes de produtores que formam a olericultora brasileira, além de garantir alta produtividade aliada à boa qualidade do produto (Luz et al., 2014; Cruz et al., 2017).

O ciclo da cultura do milho doce dura de 75 a 90 dias, o que permite vários ciclos de cultivo ao longo do ano. Pode ser cultivado sob monocultivo ou consorciado com outras plantas, sendo uma alternativa para pequenos e médios produtores (Rocha et al., 2011). Essa cultura apresenta-se como uma das mais exigentes em nutrientes, principalmente o nitrogênio (N) (Ratz, 2014;
Santos et al., 2019). Contudo, em geral, a quantidade de $\mathrm{N}$ presente no solo naturalmente é insuficiente para prover a demanda da cultura (Gomes et al., 2007), de modo que seu cultivo geralmente necessita da utilização de fontes externas de alto custo. Dado o exposto, o manejo inadequado desse macronutriente pode acarretar consideráveis reduções na produtividade de grãos (10 a 22\%) por atuar em todas as fases fenológicas da cultura, o que gera prejuízos a produtores (Subedi e Ma, 2009).

Nesse contexto, bactérias promotoras de crescimento em plantas (BPCP) são uma alternativa promissora e de baixo impacto ambiental para aumentar a eficiência da aquisição de nutrientes pela planta, pois reduz o uso fertilizantes nitrogenados e garante altas produtividades com melhor relação custobenefício (Spolaor et al., 2016). As BPCP compreendem um grupo de microrganismos que podem estimular o crescimento e o desenvolvimento das plantas por meio da secreção de hormônios e enzimas, e auxiliando a absorção de nutrientes nas espécies vegetais (Hungria et al., 2010; Aquino et al., 2019).

$\mathrm{Na}$ cultura do milho, diversos trabalhos demonstram o aumento de produtividade de grãos quando inoculados por bactérias (Quadros et al., 2014; Spolaor et al., 2016; Vendruscolo et al., 2018; Aquino et al., 2019), entretanto, trabalhos com o uso de inoculantes contendo BPCP e às respostas sobre $\mathrm{o}$ desenvolvimento $\mathrm{e}$ a produtividade da cultura do milho doce ainda são escassos. Dessa forma, com o presente trabalho objetivou-se avaliar a influência de bactérias promotoras de crescimento em plantas nativas do Sertão alagoano associadas a adubação nitrogenada na produção do milho doce.

\section{Material e Métodos}

O estudo foi realizado na área experimental da Universidade Federal de Alagoas (UFAL), localizada no munícipio de Arapiraca ( $9^{\circ} 45^{\prime} 58^{\prime}$ " de latitude Sul, $35^{\circ} 38^{\prime}$ 58" de longitude Oeste, e $264 \mathrm{~m}$ de altitude), Agreste de Alagoas. O cultivo foi realizado entre 27 de março e 10 junho de 2019. Os indicadores climáticos da região são: temperatura média anual de $25^{\circ} \mathrm{C}$ e precipitação pluvial anual média de 750 a $1000 \mathrm{~mm}$, com $50 \%$ da chuva anual ocorrendo entre maio e julho, sendo a primavera e o verão o período seco da 
região (Nimer, 1977). Dados meteorológicos do período de cultivo foram obtidos através de estação agrometeorológica automática instalada em Arapiraca e gerida pelo Instituto Nacional de Meteorologia (INMET).

A temperatura média $\left(\mathrm{T}_{\mathrm{MED}}\right)$, durante $\mathrm{o}$ período experimental, foi de $26,1 \pm 1,1{ }^{\circ} \mathrm{C}$, em que variou de $28,8^{\circ} \mathrm{C}\left(27\right.$ de março) a $23,4^{\circ} \mathrm{C}(07$ de junho). A umidade relativa do ar média (UR $\mathrm{UED}_{\text {MED }}$ variou de $90,5 \%$ (09 de maio) a $67 \%$ (05 de junho), a média geral foi de $77,55 \pm 5,5 \%$. A precipitação pluvial (chuva) acumulada durante o período experimental foi de $174,4 \mathrm{~mm}$, e 01 de abril foi o dia que registrou maior acúmulo diário de chuva, 33 mm (Figura 1).

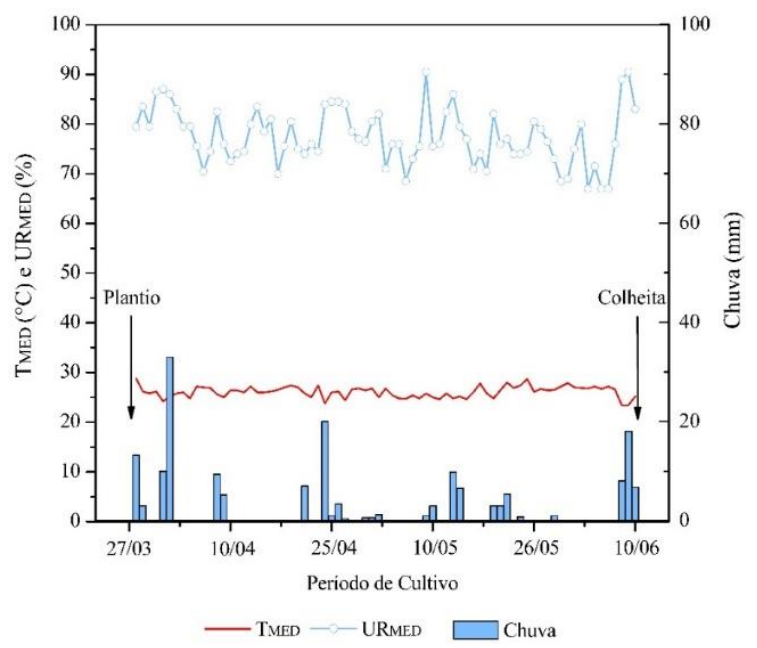

Figura 1 Temperatura média diária $-\mathrm{T}_{\mathrm{MED}}\left({ }^{\circ} \mathrm{C}\right)$, umidade relativa do ar média diária - $\operatorname{UR}_{\mathrm{MED}}(\%) \mathrm{e}$ precipitação pluvial - chuva $(\mathrm{mm})$ na região Arapiraca, AL, 2019

O solo da área experimental é classificado como Latossolo Vermelho distrófico (Embrapa, 2013). O solo foi preparado através de duas gradagens, 30 e 5 dias antes da semeadura, respectivamente. As características químicas do solo $(0-20 \mathrm{~cm})$ antes da instalação do experimento encontram-se na Tabela 1.

$\mathrm{O}$ experimento foi disposto em delineamento estatístico em blocos casualizados, com oito tratamentos e quatro repetições. Os tratamentos foram a combinação de adubação nitrogenada
$(\mathrm{N})$, baseadas na recomendação para a cultura do milho verde (Martinez et al., 1999) e BPCP nativas do sertão alagoano, pertencentes aos gêneros Pseudomonas $\left(\mathrm{SHS}_{2}, \mathrm{SHS}_{3}, \mathrm{SHS}_{9}\right)$, Bacillus $\left(\mathrm{AD}_{47}\right)$ e Enterobacter $\left(\mathrm{AD}_{3}\right)$, extraídas de raízes de plantas dos gêneros Piptadênia e Stylosanthes. Os tratamentos foram: $\mathrm{T}_{1}=50 \% \mathrm{de}$ $\mathrm{N}+\mathrm{SHS}_{2}, \mathrm{~T}_{2}=50 \%$ de N $+\mathrm{SHS}_{3}, \mathrm{~T}_{3}=50 \%$ de $\mathrm{N}+\mathrm{SHS}_{9}, \mathrm{~T}_{4}=50 \%$ de $\mathrm{N}+\mathrm{AD}_{47}, \mathrm{~T}_{5}=50 \%$ de $\mathrm{N}+\mathrm{AD}_{3}, \mathrm{~T}_{6}=0 \%$ de $\mathrm{N}$ (testemunha), $\mathrm{T}_{7}=100 \%$ de $\mathrm{N}$ e $\mathrm{T} 50 \%$ de $\mathrm{N}$. Ureia foi a fonte de $\mathrm{N}$ utilizada. A área total do experimento foi de 307,2 $\mathrm{m}^{2}$, cada parcela possuía 3,0 x 3,2 $\mathrm{m}\left(9,6 \mathrm{~m}^{2}\right)$, a semeadura da cultivar SV 9298 PRO foi realizada no espaçamento $0,25 \times 0,80 \mathrm{~m}$, formando uma população de 48 plantas por parcela, e sendo equivalente a uma população de 50 mil plantas por hectare. A área útil da parcela foi de $2,0 \mathrm{~m}^{2}$.

Para preparo dos tratamentos, incialmente foi produzida uma solução nutritiva, conforme Vincent (1970). Essa solução foi autoclavada e, em seguida, as bactérias pertencentes aos gêneros estudados foram aplicadas e levadas a uma incubadora shaker para crescimento com agitação durante 24 horas. Os diferentes inoculantes foram aplicados de forma a disponibilizar a concentração bacteriana de $1 \times 10^{6}$ células por cada $70 \mathrm{~g}$ de semente. A aplicação das bactérias também foi repetida nos estádios fenológicos V4 e V8 (quarta e oitava folha da planta totalmente expandida), na proporção $1,2 \mathrm{ml}$ do inoculante para 2 litros de água destilada, sendo distribuído $150 \mathrm{ml} \mathrm{m}^{-1}$ da mistura nas linhas de cultivo. A adubação nitrogenada foi aplicada nas fases fenológicas V4 e V8, de acordo as proporções de cada tratamento, sendo aplicado como $100 \%$ da dose, $100 \mathrm{~kg} \mathrm{ha}^{-1}$ de $\mathrm{N}$.

A adubação de fundação também foi realizada de acordo recomendação para a cultura do milho verde. Foi necessária a aplicação de $100 \mathrm{~kg} \mathrm{ha}^{-1}$ de fósforo $(\mathrm{P})$, a fonte utilizada foi o fertilizante super simples $\left(\begin{array}{lll}18 \% & \mathrm{P}_{2} \mathrm{O}_{5}\end{array}\right)$. Na adubação de cobertura necessitou-se de $40 \mathrm{~kg} \mathrm{ha}^{-1}$ de potássio $(\mathrm{K})$, foi utilizado o fertilizante cloreto de potássio como fonte de $\mathrm{K}\left(57,8 \% \mathrm{~K}_{2} \mathrm{O}\right)$.

Tabela 1 Característica químicas do solo da área experimental

\begin{tabular}{|c|c|c|c|c|c|c|c|c|c|}
\hline $\mathrm{pH}$ & $\mathrm{P}$ & K & $\mathrm{Na}$ & $\mathrm{Ca}^{2+}$ & $\mathrm{Mg}^{2+}$ & $\mathrm{Al}^{3+}$ & $\mathrm{H}^{+}+\mathrm{Al}^{3+}$ & CTC & SB \\
\hline 5,6 & 11 & 109 & 12 & 2,1 & 0,8 & 0,09 & 1,2 & 2,62 & 68 \\
\hline
\end{tabular}


A irrigação do experimento foi realizada pelo método localizado, com sistema de irrigação por gotejamento, com turno de rega diário, sendo realizada uma rega por dia. A lâmina líquida requerida foi obtida em função da evapotranspiração da cultura (ETc), sendo a ETc estimada pelo método do coeficiente da cultura $\left(\mathrm{K}_{\mathrm{C}}\right)$, que consiste na multiplicação da evapotranspiração de referência $\left(\mathrm{ET}_{0}\right)$ por Penman-Monteith-FAO (Allen et al., 1998) e o $\mathrm{K}_{\mathrm{C}}$, conforme Doorenbos e Kassam (1979).

As variáveis foram avaliadas durante a colheita da área de cultivo aos 76 DAS, na fase fenológica R4, caracterizada por grãos pastosos, estágio ideal para industrialização do milho doce. Foram avaliadas: altura de plantas (AP), número de folhas (NF), diâmetro do colmo (DC), altura de inserção da espiga (AIE), índice de luminosidade (IL), peso (PCP), diâmetro (DCP) e comprimento da espiga com palha (CCP), peso (PSP), diâmetro (DSP) e comprimento da espiga sem palha (CSP), número de grãos na fileira (NGF), número de fileiras por espiga (NFE), produtividade de espigas com palha (PROCP), peso de grãos por espiga (PG) e produtividade de grãos (PROG). A altura de plantas foi obtida do nível do solo ao pendão da planta com uso trena métrica, altura de inserção da espiga também foi obtida com trena. O diâmetro do colmo foi medido $25 \mathrm{~cm}$ acima do nível do solo, e o diâmetro de espiga foi medido na região central dela, ambas variáveis foram obtidas com paquímetro digital. O índice de luminosidade foi obtido com uso do aparelho colorímetro na quinta folha total expandida em sentido descendente a partir do ápice da planta. A pesagem das espigas para obtenção da produtividade foi obtida em balança com precisão de $0,001 \mathrm{~g}$.

Os dados obtidos foram submetidos a análise de variância e, quando significativos pelo teste $F$ $(\mathrm{p} \leq 0,05)$, tiveram suas médias comparadas pelo teste de Scott-Knott a 5\% de probabilidade.

\section{Resultados e Discussão}

A inoculação de BPCP e $\mathrm{N}$ resultaram em efeitos significativos para as variáveis: diâmetro do colmo, diâmetro de espiga com palha, diâmetro de espiga sem palha, peso de espiga com palha, peso de grãos por espiga, produtividade de espigas com palha, e produtividade de grãos (Tabela 2). As demais variáveis não foram significativas.

Tabela 2 Médias de diâmetro do colmo (DC), diâmetro de espiga com palha (DCP), diâmetro de espiga sem palha (DSP), peso de espiga com palha (PCP), peso de grãos por espiga (PG), produtividade de espigas com palha (PROCP), produtividade de grãos (PROG), altura de plantas (AP), número de folhas (NF), altura de inserção da espiga (AIE), índice de luminosidade (IL), comprimento de espigas com palha (CCP) e sem palha (CSP), peso de espigas sem palha (PSP), número de grãos por fileira (NGF), número de fileiras por espiga (NFE) em função da aplicação de bactérias promotoras de crescimento nativas do sertão alagoano mais adubação nitrogenada

\begin{tabular}{|c|c|c|c|c|c|c|c|c|c|}
\hline Tratamentos & \multicolumn{2}{|c|}{$\begin{array}{l}\mathrm{DC} \\
\mathrm{mm}\end{array}$} & $\begin{array}{l}\text { DCP } \\
---- \\
\end{array}$ & $\begin{array}{l}\text { DSP } \\
\text { m ---- }\end{array}$ & \multicolumn{3}{|l|}{ PCP } & \multicolumn{2}{|c|}{$\begin{array}{l}\text { PROCP PROG } \\
\text { t } \mathrm{ha}^{-1}\end{array}$} \\
\hline $50 \%$ de $\mathrm{N}+\mathrm{SHS} 2$ & & & $6,51 \mathrm{a}$ & $5,62 \mathrm{a}$ & $457,05 \mathrm{a}$ & & $196,53 \mathrm{a}$ & $22,85 \mathrm{a}$ & $9,82 \mathrm{a}$ \\
\hline $50 \%$ de $\mathrm{N}+\mathrm{SHS} 3$ & 23 & & $6,67 \mathrm{a}$ & $5,73 \mathrm{a}$ & $475,07 \mathrm{a}$ & & $204,28 \mathrm{a}$ & $23,75 \mathrm{a}$ & $10,21 \mathrm{a}$ \\
\hline $50 \%$ de $\mathrm{N}+\mathrm{SHS} 9$ & 24, & & $6,63 \mathrm{a}$ & $5,68 \mathrm{a}$ & $466,62 \mathrm{a}$ & & $200,64 \mathrm{a}$ & $23,33 \mathrm{a}$ & $10,03 \mathrm{a}$ \\
\hline $50 \%$ de $\mathrm{N}+\mathrm{AD} 47$ & 23 & & $6,65 \mathrm{a}$ & $5,71 \mathrm{a}$ & $486,07 \mathrm{a}$ & & $209,01 \mathrm{a}$ & $24,30 \mathrm{a}$ & $10,45 \mathrm{a}$ \\
\hline $50 \%$ de $\mathrm{N}+\mathrm{AD} 3$ & 23 & & $6,62 \mathrm{a}$ & $5,71 \mathrm{a}$ & $466,15 \mathrm{a}$ & & 200,44 a & $23,31 \mathrm{a}$ & $10,02 \mathrm{a}$ \\
\hline $0 \%$ de $\mathrm{N}$ & 21, & & $6,35 \mathrm{~b}$ & $5,48 \mathrm{~b}$ & $400,12 \mathrm{~b}$ & & $172,05 \mathrm{~b}$ & $20,00 \mathrm{~b}$ & $8,60 \mathrm{~b}$ \\
\hline $100 \%$ de $\mathrm{N}$ & & & $6,64 \mathrm{a}$ & $5,68 \mathrm{a}$ & $475,82 \mathrm{a}$ & & $192,05 \mathrm{a}$ & $23,79 \mathrm{a}$ & $10,23 \mathrm{a}$ \\
\hline $50 \%$ de $\mathrm{N}$ & 23, & & $6,39 \mathrm{~b}$ & $5,62 \mathrm{a}$ & $445,32 \mathrm{a}$ & & $191,48 \mathrm{a}$ & $22.26 \mathrm{a}$ & $9,57 \mathrm{a}$ \\
\hline Teste F & & & $0,06^{*}$ & $0,02 *$ & $2880,49^{*}$ & & $5,42 *$ & $5,32^{*}$ & $7,89^{*}$ \\
\hline \multirow[t]{2}{*}{$\mathrm{CV}(\%)$} & & & 2,47 & 1,53 & 5,26 & & 6,68 & 6,69 & 6,60 \\
\hline & $\begin{array}{c}\text { AP } \\
\text { m }\end{array}$ & $\begin{array}{c}\mathrm{NF} \\
\text { unid. }\end{array}$ & $\begin{array}{c}\mathrm{AIE} \\
\mathrm{m}\end{array}$ & IL & $\begin{array}{c}\mathrm{CCP} \\
--\mathrm{cm}\end{array}$ & CSP & $\begin{array}{c}\text { PSP } \\
\mathrm{g}\end{array}$ & $\begin{array}{l}\text { NGF } \\
---- \text { unid. }\end{array}$ & NFE \\
\hline Média Geral & 2,26 & 10,39 & 1,09 & 0,25 & 30,20 & 21,95 & 334,97 & 34,10 & 16,23 \\
\hline Teste F & $0,04^{\mathrm{ns}}$ & $0,15^{\mathrm{ns}}$ & $0,00^{\mathrm{ns}}$ & $0,00^{\text {ns }}$ & $2,91^{\mathrm{ns}}$ & $0,32^{\text {ns }}$ & $1684,10^{\text {ns }}$ & $5,42^{\mathrm{ns}}$ & $0,57^{\mathrm{ns}}$ \\
\hline $\mathrm{CV}(\%)$ & 6,34 & 3,90 & 4,72 & 9,74 & 4,41 & 3,42 & 8,81 & 5,80 & 3,46 \\
\hline
\end{tabular}

Médias seguidas da mesma letra nas colunas não diferem entre si pelo teste de Scott-Knott $(\mathrm{p} \leq 0,05)$; ${ }^{\text {ns }} \mathrm{e} *$ : não significativo e significativo a $5 \%$ de probabilidade pelo teste $\mathrm{F}$, respectivamente; $\mathrm{CV}(\%)$ é coeficiente de variação. 
$\mathrm{O}$ milho doce submetido à $50 \%$ de $\mathrm{N}$ combinado com BPCP não apresentou diferença significativa no desempenho produtivo quando comparado a tratamento que recebeu $100 \%$ de N, o que demonstra potencial na adoção dessas BPCP em substituição de parte da adubação nitrogenada, gerando economia e uma produção de milho doce menos dependente de fertilizantes químicos. Spolaor et al. (2016) e Aquino et al. (2019) afirmam que BPCP aumentam a produção de fitormônios que induzem o crescimento radicular e melhoram a absorção de água e nutrientes pelo milho, principalmente $o$ nitrogênio gasoso que passa a ser disponibilizado a cultura.

Para o diâmetro do caule (DC), tratamentos com BPCP obtiveram uma média geral de 23,59 $\pm 0,38 \mathrm{~mm}$, e sob 50 e $100 \%$ de $\mathrm{N}$ foram obtidos diâmetros médios de 23,09 $\pm 0,33$ e 24,09 $\pm 0,29$ $\mathrm{mm}$, respectivamente. $\mathrm{O}$ tratamento que não recebeu adubação nitrogenada e bactérias obteve um DC de 21,34 $\pm 0,33 \mathrm{~mm}$, sendo inferior aos tratamentos com BPCP e adubação nitrogenada de 50 e $100 \%$ em 9,53, 7,57 e 11,41\%, respectivamente. Plantas com maior DC tendem a maximizar a produtividade do milho, gerando maior capacidade de transporte e armazenamento de fotoassimilados que participarão no enchimento de grãos (Penariol et al., 2003). Isso demonstra que a inoculação de BPCP aliada à adubação nitrogenada favorece $\mathrm{o}$ aumento normal em DC no milho doce, se igualando a cultivos que recebem $100 \%$ da adubação nitrogenada requerida, podendo gerar incremento produtivo e, além disso, economia em adubação com fertilizante químico.

$\mathrm{O}$ diâmetro de espiga com palha (DCP) não diferiu entre os tratamentos que receberam BPCP e sob adubação com $100 \%$ de $\mathrm{N}$, com média geral de 6,61 $\pm 0,06 \mathrm{~cm}$ para tratamentos com bactérias e $6,64 \pm 0,08 \mathrm{~cm}$ com adubação de $100 \%$ de $\mathrm{N}$. Porém, esses tratamentos superaram os que receberam apenas $50 \%$ de $\mathrm{Ne} 0 \%$ de $\mathrm{N}$, esses, por sua vez, produziram um DCP médio de 6,39 \pm 0,06 e $6,35 \pm 0,07 \mathrm{~cm}$, respetivamente, sendo 3,32 e $3,39 \%$ menores em relação à média geral dos tratamentos com BPCP, e 3,76 e 4,36\% menores em relação ao tratamento com $100 \%$ de N. Quanto ao diâmetro de espiga sem palha (DSP), todas as combinações de adubação nitrogenada aliadas a bactérias e as doses de 50 e $100 \%$ de $\mathrm{N}$, superaram o tratamento com $0 \%$ de
$\mathrm{N}$, porém, não diferiram entre si, resultando em uma média geral de 5,67 $\pm 0,04 \mathrm{~cm}$, enquanto, $0 \%$ de $\mathrm{N}$ obteve média de $5,48 \pm 0,07 \mathrm{~cm}$, sendo $3,35 \%$ menor.

Freire et al. (2010) estudaram doses de nitrogênio na cultura do milho verde, e não observaram significância para $\mathrm{o}$ diâmetro de espigas com palha, mas espigas sem palha apresentaram diâmetro máximo de $4,9 \mathrm{~cm}$, com dose estimada de $136 \mathrm{~kg} \mathrm{ha}^{-1}$ de $\mathrm{N}$, o que apontou incremento no diâmetro de espigas sem palha em resposta ao aumento da dose de N. Esses resultados ratificam os dados obtidos nesse trabalho, em que tratamentos que receberam doses maiores de N e BPCP superaram os de menores doses, o que confirma que a nutrição nitrogenada adequada do milho doce favorece um maior diâmetro de espigas, e que BPCP são capazes de garantir essa nutrição para a cultura.

Quanto ao peso de espiga com palha (PCP), tratamentos em que a adubação nitrogenada foi combinada com BPCP obtiveram desempenho igual àqueles que receberam 50 e $100 \%$ de $\mathrm{N}$, o que resultou em média geral de 467,44 $\pm 13,38 \mathrm{~g}$ por espiga. Esses tratamentos superaram o PCP de plantas sob $0 \%$ de $\mathrm{N}$ em $14,40 \%$. O peso de grãos por espiga (PG) foi semelhante a variável $\mathrm{PCP}$, em que os tratamentos com BPCP e aqueles com 50 e $100 \%$ de $\mathrm{N}$ não diferiram entre si, e obtiveram um desempenho média geral de 199,20 $\pm 6,37$ g por espiga, e superaram o tratamento $0 \%$ de $\mathrm{N}$ em 13,62\%. Freire et al. (2010) afirmam que o peso da espiga e grãos estão ligados a nutrição da planta e condições climáticas, em que havendo maior disponibilidade e absorção de $\mathrm{N}$, eficiência no uso da água e captação de luz solar, condições proporcionadas por BPCP, o milho produz espigas de maior peso. Isso ratifica os resultados obtidos nessa pesquisa, em que áreas sob maior disponibilidade de $\mathrm{N}$ e com BPCP alcançaram maiores pesos de espiga.

Tratamentos com BPCP, 100 e $50 \%$ de N obtiveram desempenhos semelhantes para as variáveis produtividade de espigas com palha (PROCP) e produtividade de grãos (PROG), não diferindo estatisticamente, porém, todos superaram o tratamento $0 \%$ de N. Quanto a PROCP, sob $0 \%$ de $\mathrm{N}$ o milho doce produziu $20,00 \pm 0,47 \mathrm{t} \mathrm{ha}^{-1}$, desempenho produtivo $15,07 \%$ menor em relação aos demais tratamentos, esses por sua vez obtiveram uma 
PROCP média geral de 23,55 $\pm 0,50 \mathrm{t} \mathrm{ha}^{-1}$. Quanto a PROG, o milho doce sob $0 \%$ de $\mathrm{N}$ produziu $8,60 \pm 0,26 \mathrm{t} \mathrm{ha}^{-1}$, enquanto os demais tratamentos obtiveram uma média geral de 10,04 $\pm 0,28 \mathrm{t} \mathrm{ha}^{-1}$, o que resultou em ganho produtivo de $14,34 \%$ quando comparado com a testemunha.

Araújo et al. (2014) em estudo que combinou BPCP e adubação nitrogenada no milho verde, obtiveram aumento de $30 \%$ na produtividade de espigas com redução de $15 \%$ da adubação nitrogenada exigida pela cultura. Esse incremento em produtividade pode representar um retorno econômico positivo, conforme foi observado por Vendruscolo et al. (2018), que evidenciaram que gastos para realização de cultivos com a inoculação de bactérias Azospirillum brasilense em sementes pouco interferem sobre os custos totais de produção do milho doce. Mediante os resultados citados e os dados obtidos nessa pesquisa, verifica-se que a aplicação de BPCP aliada a doses menores de adubação nitrogenada do que aquela recomendada para o milho doce, pode ser capaz de manter um alto desempenho produtivo da cultura.

Áreas de cultivo de milho doce sob menor dose de adubação nitrogenada de forma isolada ou associada a BPCP nativas de Alagoas, apresentam desempenho produtivo igual a áreas que recebem $100 \%$ da dose recomendada com ureia, o que indica que é possível obter uma alta produtividade em cultivos de milho doce com menor disponibilidade de N. Porém, torna-se importante salientar que são necessários mais estudos sobre a aplicação de BPCP nativas e doses de $\mathrm{N}$ no cultivo do milho doce, o que tornaria possível determinar qual a forma mais eficiente de fornecer $\mathrm{N}$ e a dose adequada para cultivos de milho doce no Agreste alagoano.

\section{Conclusão}

A redução da adubação nitrogenada de 100 para $50 \mathrm{~kg} \mathrm{ha}^{-1}$ de nitrogênio, associada ou não as $\mathrm{BPCP}$, é viável na manutenção da produtividade do milho doce no Agreste alagoano.

\section{Referências}

Allen, R. G.; Pereira, L. S.; Raes, D.; Smith, M. Crop evapotranspiration: guidelines for computing crop water requirements. Rome: Food Agriculture Organization of the United Nations, 1998. 301p.
Aragão, C. A. Avaliação de híbridos simples braquíticos de milho super doce (Zea mays) portadores do gene shrunken (sh2sh2) utilizando esquema dialélico parcial. 2002.97 f. Tese (Doutorado em Agronomia). Universidade Estadual de São Paulo, Botucatu, 2002.

Araujo, R. M.; Araujo, A. S. F.; Nunes, L. A. P. L.; Figueiredo, M. V. B. Resposta do milho verde à inoculação com Azospirillum brasilense e níveis de nitrogênio. Ciência Rural, v. 44, n. 9, p. 1556-1560, 2014. https://doi.org/10.1590/0103$8478 \mathrm{cr} 20130355$

Aquino, J. P. A.; Macedo Júnior, F. B.; Antunes, J. E. L.; Figueiredo, M. V. B.; Alcântara Neto, F.; Araujo, A. S. F. Plant growth-promoting endophytic bacteria on maize and sorghum. Pesquisa Agropecuária Tropical, v. 49, e5624, 2019. http://dx.doi.org/10.1590/1983$40632019 \mathrm{v} 4956241$

Camilo, J. S.; Barbieri, V. H. B.; Rangel, R. M.; Bonnas, D. S.; Luz, J. M. Q.; Oliveira, R. C. Aceitação sensorial de híbridos de milho doce e híbridos de milho verde em intervalos de colheita. Revista Ceres, v. 62, n. 1, p. 1-8, 2015. https://doi.org/10.1590/0034-737X201562010001

Cruz, S.C.S.; Soares, G. F.; Duarte, T. C.; Machado, C. G.; Sena Júnior, D. G. Milho doce cultivado em arranjo espacial convencional e equidistante submetido a níveis de adubação. Revista Espacios, v. 38, n. 38, p. 15-24, 2017. https://www.revistaespacios.com/a17v38n38/a17v38n38p 15.pdf

Doorenbos, J.; Kassam, A. H. Yield response to water. Irrigation and drainage paper, n. 33, p. 257, 1979.

Empresa brasileira de pesquisa agropecuária (EMBRAPA). Sistema brasileiro de classificação de solos. 3.ed. Brasília, 2013. 353 p.

Ferreira, P. A.; Guimarães, S. M.; Magalhães, P. J.; Ximenes, P. A. Caracteres agronômicos e nutricionais de genótipos de milho doce. Bioscience Journal, v. 25, n. 1, p. 104-112, 2009.

http://www.seer.ufu.br/index.php/biosciencejournal/articl e/view/6828

Ferreira, M. G. P.; Brito, M. E. B.; Costa, F. B.; Araújo Filho, G. D.; Alvino, F. C. G. Aspectos químicos e físicos dos grãos de milho doce sob 
estresse hídrico. Revista Brasileira de Agrotecnologia, v. 1, n. 1, p. 1-6, 2011. https://pdfs.semanticscholar.org/12f1/462b239b61f3d405 $86 \mathrm{c} 5 \mathrm{c} 5 \mathrm{~d} 12 \mathrm{dbb} 8 \mathrm{fe} 94 \mathrm{~d} 7 \mathrm{~b} . \mathrm{pdf}$

Freire, F. M.; Viana, M. C. M.; Mascarenhas, M. H. T.; Pedrosa, M. W.; Coelho, A. M.; Andrade, C. L. T. Produtividade econômica e componentes da produção de espigas verdes de milho em função da adubação nitrogenada.

Revista Brasileira de Milho e Sorgo, v. 9, n. 3 p. 213-222, 2010. http://dx.doi.org/10.18512/19806477/rbms.v9n3p213-222

Gomes, R. F.; Silva, A. G.; Assis, R. L.; Pires, F. R. Efeito de doses e da época de aplicação de nitrogênio nos caracteres agronômicos da cultura do milho sob plantio direto. Revista Brasileira de Ciência do Solo, v. 31, n. 5, p. 931-938, 2007. http://dx.doi.org/10.1590/s010006832007000500010

Gondim, J. P. E. Influência da pré-embebição na germinação em sementes de milho doce. In: Silva-Matos. Avanços científicos e tecnológicos nas ciências agrárias. Ponta Grossa, 2020, p. 65-71.

Hungria, M.; Campo, R. J.; Souza, E. M. Pedroso, F. O. Inoculation with selected strains of Azospirillum brasilense and A. lipoferum improves yields of maize and wheat in Brazil. Plant and Soil, v. 331, n. 1, p. 413-425, 2010. https://doi.org/10.1007/s11104-009-0262-0

Luz, J. M. Q.; Camilo, J. S.; Barbieri, V. H. B.; Rangel, R. M.; Oliveira, R. C. Produtividade de genótipos de milho doce e milho verde em função de intervalos de colheita. Horticultura Brasileira, v. 32, n. 2, p. 163-167, 2014. http://dx.doi.org/10.1590/S0102-05362014000200007

Martinez, H. E. P. Diagnose foliar. In: RIBEIRO, A. C. (Editor). Recomendações para o uso de corretivos e fertilizantes em Minas Gerais: $5^{\text {a }}$ aproximação. Viçosa: Comissão de Fertilidade do Solo do Estado de Minas Gerais, 1999, p. 143-168.

Nimer, E. Geografia do Brasil: Região Nordeste. $2^{\mathrm{a}}$ ed. Rio de Janeiro, 1977.

Penariol, F. G.; Sieri Filho, D. F.; Coicev, L.; Bordin, L. Comportamento de cultivares de milho semeadas em diferentes espaçamentos entre linhas e densidades populacionais, na safrinha. Revista Brasileira de Milho e Sorgo, v. 2 , p. 52-60, 2003. https://doi.org/10.18512/19806477/rbms.v2n2p52-60

Quadros, P. D.; Roesch, L. F. W.; Silva, P. R. F.; Vieira, V. M.; Roesch, D. D.; Camargo, F. A. O. Desempenho agronômico a campo de híbridos de milho inoculados com Azospirillum. Revista Ceres, v. 61, n. 2, p. 209-218, 2014. https://doi.org/10.1590/S0034-737X2014000200008

Ratz, R. J. Uso de bactérias do gênero Bacillus como promotoras de crescimento para a cultura do milho e soja. 2014. 71 f. Dissertação (Mestrado em Engenharia Química) Universidade Estadual do Oeste do Paraná, Toledo, 2014.

Rocha, D. R.; Fornasier filho, D.; Barbosa, J. C. Efeitos da densidade de plantas no rendimento comercial de espigas verdes de cultivares de milho. Horticultura Brasileira, v. 29, n. 3, p. 392-397, 2011. https://doi.org/10.1590/S010205362011000300023

Santos, W. F.; Santos, L. F. S.; Pelúzio, J. M.; Pereira, J. S.; Reais, I. M.; Silva, R. M. Resposta e eficiência agronômica em genótipos de milho à adubação nitrogenada no Sul do Pará. Pesquisa Agropecuária Tropical, v. 24, n. 2, p. 1-5, 2019. https://doi.org/10.12661/pap.2019.010

Spolaor, L. T.; Gonçalves, L. S. A.; Santos, O. J. A. P.; Oliveira, A. L. M.; Scapim, C. A.; Bertagna, F. A. B., Kuki, M. C. Bactérias promotoras de crescimento associadas a adubação nitrogenada de cobertura no desempenho agronômico de milho pipoca. Bragantia, v. 75, n. 1, p. 33-40, 2016. http://dx.doi.org/10.1590/1678-4499.330

Subedi, K. D.; Ma, B. L. Assessment of some major yield-limiting factors on maize production in a humid temperate environment. Field Crops Research, v. 110, n. 1, p. 21-26, 2009. https://doi.org/10.1016/j.fcr.2008.06.013

Vendruscolo, E. P.; Siqueira, A. P. S.; Rodrigues, A. H. A.; Oliveira, P. R.; Correia, S. R.; Seleguini, A. Viabilidade econômica do cultivo de milho doce submetido à inoculação com Azospirillum brasilense e soluções de tiamina. Revista de Ciências Agrárias, v. 61, p. 1-7, 2018. http://dx.doi.org/10.22491/rca.2018.2674

Vincent, J. M. A. Manual for the practical study of root nodule bacteria. Oxford, 1970. 440p. 